\title{
Agitator tank device and drag reduction agent evaluation
}

\author{
ZHANG Fan(张 帆) ${ }^{1,2}$, XIAO Bo-yuan(肖博元) $)^{1}$, TANG Yang-hao(汤养浩) $)^{3}$, LUO Qi-rong(罗旗荣) ${ }^{3}$ \\ (1. Beijing Key Laboratory of Urban Oil and Gas Distribution Technology, China University of Petroleum (Beijing), \\ Beijing 102249, China; \\ 2. Institute of Mechanics, Chinese Academy of Science, Beijing 100080, China; \\ 3. Administation Bureau of Shangdong Liaocheng Oil Transportation, Liaocheng 252000, China)
}

\begin{abstract}
The device that consists of tank and disk agitator for evaluation drag reduction agents (DRA) was established. The effect of DRA was defined by testing the changes of agitator torque that drives the disk rotation. The HG-DRA for oil pipeline from Linyi to Puyang was studied by agitator tank device. The relationships between the drag reduction rate and Reynolds number, concentration, balance time were studied. The best concentration and the highest Renords number for the best drag reduction rate were confirmed. The results show that the drag reduction rate tested in agitator tank is close to that in pipeline. The maximum error of drag reduction rate between pipeline and agitator tank is $18.3 \%$, which indicates that the agitator tank device is available to evaluate the effect of DRA for pipeline and it also has the advantages of simple, easy to be operated and using small volume of oil. Those are very helpful for operaters to know the properties of DRA and operate pipeline well.
\end{abstract}

Key words: drag reduction; agitation; reynolds number; evaluation method

\section{Introduction}

Nowadays more and more crude oil and fuel oil are transported by pipelines. To cut down the friction or raise the flow rate of the pipeline, drag reduction agents (DRA) is often injected into oil in pipeline. In pipeline design, using DRA can increase the pump station spacing, it is helpful to reduce the number of pumping stations and save the investment of pipeline construction especially in very poor places such as subsea, deserts, swamps, alpine areas etc. But how to evaluate the drag reduction effect of DRA and confirm its affect factors are very important for users. There are many evaluation methods to evaluate drag reduction, including inject drag reducing agent into running pipeline to evaluate on-site $^{[1-3]}$, loop evaluation method ${ }^{[4-5]}$, rotating disk evaluation method ${ }^{[6-11]}$ and so on. The above methods have both advantages and disadvantages. The rotating disk device is different with traditional testing loop; it is easy to operate. The effect of DRA and affect factors can be defined by comparing the torques of rotating disk before and after the DRA is added in the sample. The shortage of strong shear caused by pump in loop is avoided in rotating disk device.

\section{Agitator tank device}

Agitator tank method is based on rotating disk evaluation method. The experimental platform is composed of speed control device, water bath, torque measuring instrument, agitator tank, disk impeller and inner cover of agitator. The agitator impeller shape is disk whose diameter is very close to that of tank to provide strong radial flow and high Reynolds numbers. Although the ordinary impeller of four blades or six blades can also be used, they may cause shear rate strong enough to cut off the long-chain of high polymer of DRA. The inner cover is placed just on the surface of oil agitator tank and the disk is placed in the middle between bottom and inner cover of agitator tank. Not only the cavitation caused by high speed rotation in tank is restrained but also the volatilization of oil in tank is avoided.

\section{Drag reduction in agitator tank}

According to the definition of Reynolds number, the Reynolds number is the ratio of the inertial force and the viscosity. So the agitator Reynolds number ${ }^{[12-13]}$ is:

$\operatorname{Re}=\frac{\rho r_{0}^{2} \omega}{\mu}$

where $\rho$ is density of oil, $r_{0}$ is radius of disk, $w$ is angular velocity, $\mu$ is viscosity of oil.

When disk is rotated, the resistance moment comes from both sides of disk, and the total resistance moment is: 


$$
T=4 \pi \int_{0}^{r_{0}} r_{0}^{2} \tau_{\varphi} \mathrm{d} r
$$

For Newtonian fluid,

$\tau_{\varphi}=\mu\left(\frac{\partial u_{\varphi}}{\partial y}\right)_{y=0}$

$\frac{\partial u_{\varphi}}{\partial y}=r \omega \frac{\partial G}{\partial \xi} \frac{\mathrm{d} \xi}{\mathrm{d} y}=r \omega^{\frac{3}{2}} v^{\frac{1}{2}} G$

where dimensionless distance $\xi=y \sqrt{\frac{\omega}{v}}$,

$G=G(\xi)$

According to Von Karman and Schultz-Gurnow ${ }^{[14]}$.

$T=0.5 k_{m} \rho \omega^{2} r_{0}^{5}$

where $K_{m}$ is resistance coefficient.

Drag reduction means resistance coefficient of the fluid boundary layer is decreased. And the resistance coefficient can be calculated by measured torque and angular velocity.

Drag reduction rate or effect is decided by the change of agitator torque before and after DRA is added into fluid. Drag reduction rate $(R)$ of DRA is defined as:

$R=\frac{T_{0}-T_{\mathrm{D}}}{T_{\mathrm{o}}}$

where $T_{0}$ and $T_{\mathrm{D}}$ are torques before and after DRA added into fluid, respectively.

\section{Experimental results and analysis}

\subsection{Reynolds number and drag reduction rate}

The Reynolds number in the agitator tank is related to fluid density, viscosity, disk diameter and rotation speed. In the experiment the only one that can be changed is disk rotating speed. Different speeds correspond different Reynolds number. When viscosity of oil is $67.1 \mathrm{mPa} \cdot \mathrm{s}$, Reynolds numbers at different speeds are shown in Table 1.

Table 1 Reynolds numbers at different speeds

\begin{tabular}{ccccccc}
\hline Speed $/\left(r \cdot \mathrm{min}^{-1}\right)$ & 800 & 900 & 1000 & 1100 & 1200 & 1300 \\
\hline$R e$ & 6105 & 6869 & 7631 & 8536 & 9158 & 9921
\end{tabular}

The drag reduction rate varies with Reynolds number and different concentrations of DRA. The results are shown in Fig.1. Before Reynolds number reaches 7631 at $1000 \mathrm{r} / \mathrm{min}, R$ increases with the increase of Reynolds number and then it declines after Reynolds number is more than 7 631. It is deduced that some long-chain polymers is cut off which leads drag at high-speed shearing reduction rate decline.

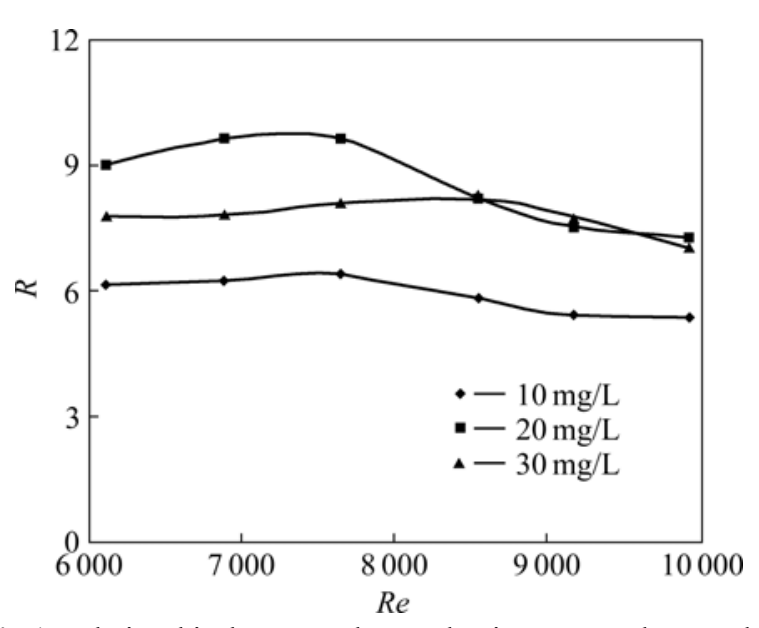

Fig.1 Relationship between drag reduction rate and Reynolds number with different concentrations of DRA

\subsection{Balance time and drag reduction rate}

It will take a period of time for DRA added into agitator tank to reach maximum or balance drag reduction rate. The drag reduction rate of $20 \mathrm{mg} / \mathrm{L}$ DRA varies with time at different rotation speeds. The results are shown in Fig.2. It is indicated that the higher rotation speed of disk, the shorter time of $R$ reaching maximum drag reduction rate. The high speed may help DRA outspread and diffuse. Yet the over high speed makes $R$ decrease.

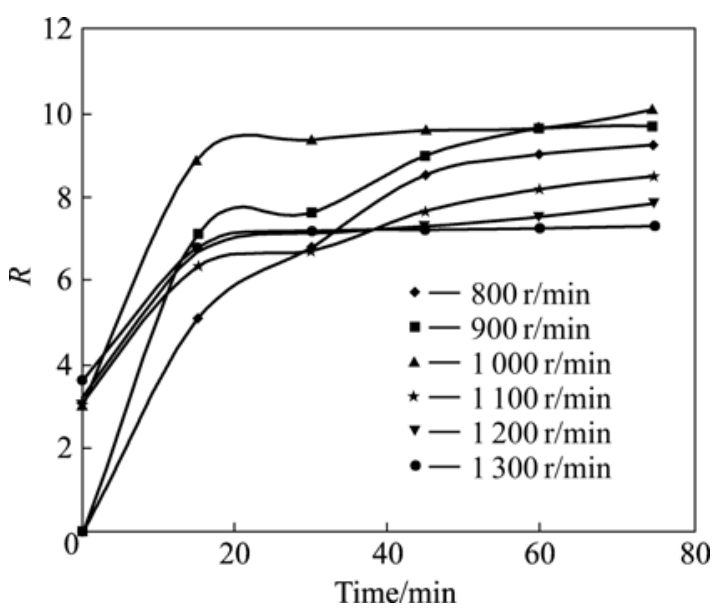

Fig.2 Relationship between drag reduction rate and time with $20 \mathrm{mg} / \mathrm{L}$ DRA

The relationship between drag reduction rate and work time with $30 \mathrm{mg} / \mathrm{L}$ RDA is shown in Fig.3.

It is shown that with DRA concentration increasing, the time of drag reduction rate reaching maximum becomes shorter.

\subsection{DRA concentration and drag reduction rate}

The relationship of DRA concentration and drag reduction rate at $1000 \mathrm{r} / \mathrm{min}$ is shown in Fig. 4. The results show that for tested oil the drag reduction rate 


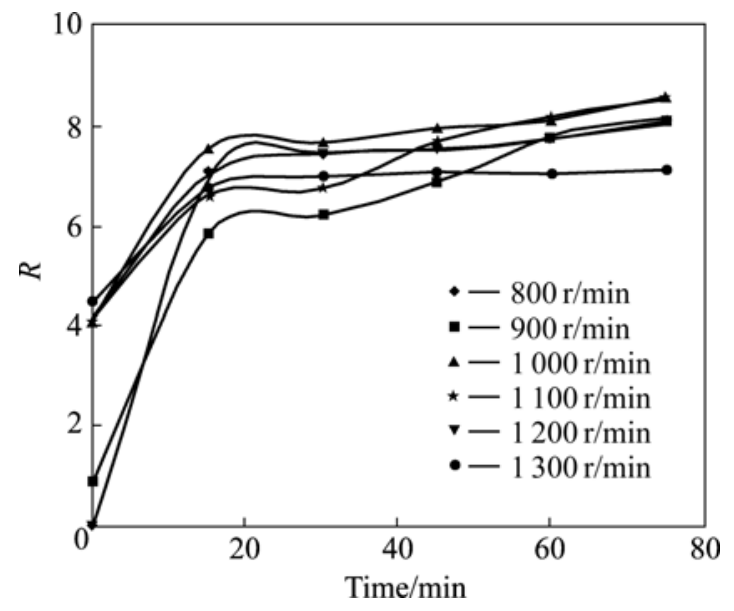

Fig.3 Relationship between drag reduction rate and time with $30 \mathrm{mg} / \mathrm{L}$ DRA

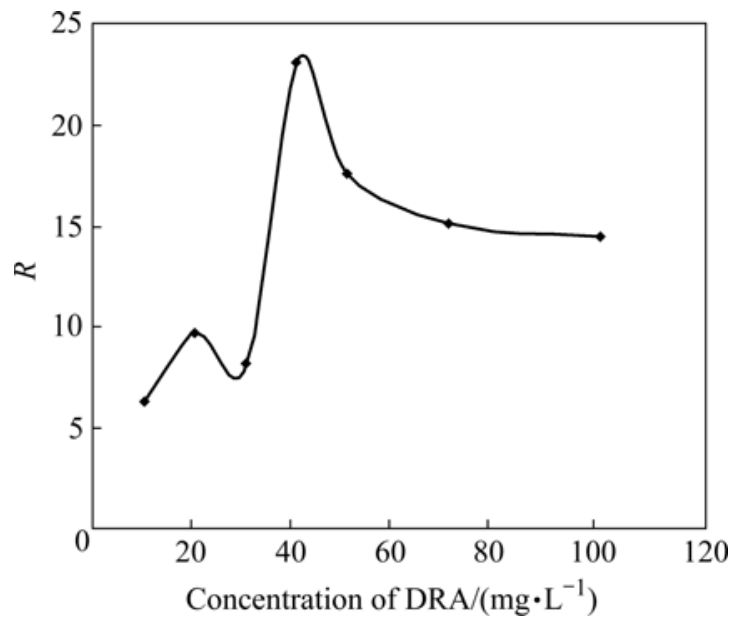

Fig.4 Relationship of $R$ and DRA concentration

reaches its peak value when DRA is $40 \mathrm{mg} / \mathrm{L}$.

\subsection{Influence of high shearing on drag reduction rate}

In order to study the high shearing influence on the drag reduction rate, diesel is stirred at different rotation speeds in agitator tank. The results are shown in Fig.5.

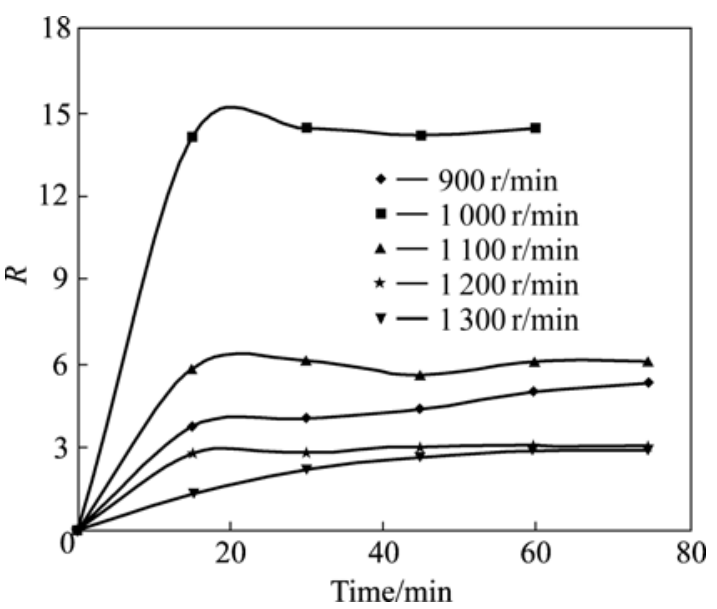

Fig.5 Relationship of drag reduction rate and rotation speed
In one hand, the higher speed is, the stronger turbulence and the higher drag reduction rate are. But in another hand, the higher speed is, the stronger shear rate then the more long-chain polymers are cut off and the drag reduction rate is decline more. So at $1000 \mathrm{r} / \mathrm{min}$, the drag reduction rate is optimum.

\section{Drag reduction agent evaluation}

It is assumed that under the same turbulent state in agitator and pipeline, Reynolds numbers are the same too $\left(R e_{a}=R e_{p}\right)$. As the effect of DRA is result of suppression turbulence, it works either in pipeline or in agitator tank device. So the $R$ tested in agitator should represent the situation in pipeline. According to above experimental results, HG drag reduction agent is evaluated with agitator tank device for Dongying-Linyi pipeline and Linyi-Puyang pipeline.

\subsection{DRA evaluation for Dongying-Linyi pipeline}

Shengli crude oil is transported by Dongying-Linyi pipeline. At $40{ }^{\circ} \mathrm{C}$, the viscosity of Shengli oil is 78 $\mathrm{mPa} \cdot \mathrm{s}$, and the density is $892.1 \mathrm{~kg} / \mathrm{m}^{3}$. The inner diameter of Dongying-Linyi pipeline is $513 \mathrm{~mm}$. The different concentrations of $\mathrm{HG}$ drag reduction agent is added into oil. At differents flow rates, the drag reduction rates in pipeline are shown in Table 2 .

Table $2 R$ of Dongying-Linyi pipeline

\begin{tabular}{ccc}
\hline Flow rate $/\left(\mathrm{m}^{3} \cdot \mathrm{h}^{-1}\right)$ & DRA concentration $/\left(\mathrm{mg} \cdot \mathrm{L}^{-1}\right)$ & $R$ \\
\hline \multirow{2}{*}{865.0} & 20 & 24.17 \\
& 15 & 16.43 \\
951.3 & 15 & 20.20 \\
923.4 & 10 & 14.67 \\
955.3 & 20 & 28.60 \\
\hline
\end{tabular}

According to the data of pipeline and oil, as well as the assumption of $R e_{a}=R e_{p}$, the corresponding experiments parameters for test $R$ in agitator tank can be fixed and the test results are listed in Table 3.

The maximum error of $R$ in pipeline and in agitator tank device is $18.3 \%$.

Table $3 R$ of agitator tank device

\begin{tabular}{ccc}
\hline $\begin{array}{c}\text { Rotation } \\
\text { speed } /\left(\mathrm{r} \cdot \mathrm{min}^{-1}\right)\end{array}$ & $\begin{array}{c}\text { DRA } \\
\text { concentration } /\left(\mathrm{mg} \cdot \mathrm{L}^{-1}\right)\end{array}$ & $R$ \\
\hline 1014 & 20 & 25.33 \\
1116 & 15 & 19.96 \\
1083 & 15 & 16.57 \\
1120 & 10 & 12.08 \\
\hline
\end{tabular}




\subsection{DRA evaluation for Linyi-Puyang pipeline}

Oman crude oil is transported by Linyi-Puyang pipeline. At $25^{\circ} \mathrm{C}$, the viscosity of Oman oil is 14.2 $\mathrm{mPa} \cdot \mathrm{s}$, and the density is $860 \mathrm{~kg} / \mathrm{m}^{3}$. The inner diameter of pipeline is $363 \mathrm{~mm}$, and the deliverability of pipeline is $8600 \mathrm{t} / \mathrm{d}$.

At different concentrations of $\mathrm{HG}$ drag reduction agent, drag reduction rates were tested in pipeline and in agitator tank device respectively. The results are shown in Table 4.

Table $4 R$ in agitator tank device and in pipeline

\begin{tabular}{cccc}
\hline DRA concentration $/\left(\mathrm{mg} \cdot \mathrm{L}^{-1}\right)$ & 10 & 15 & 20 \\
\hline$R$ in agitator tank & 16.4 & 31.8 & 39.0 \\
$R$ in pipeline & 15.0 & 30.7 & 40.3 \\
\hline
\end{tabular}

The results show that the drag reduction rates measured in agitator tank device and in Linyi-Puyang pipeline are very close.

\section{Conclusions}

1) A agitator tank device for DRA evaluation is established. It is easy to be operated. The shortage of strong shear rate caused by pump in loop is avoided in agitator tank device.

2) With agitator tank device, DRA can be evaluated according to the changes of agitator torque before and after DRA added into fluid.

3) The higher rotation speed of disk, the shorter time of $R$ reaching its balance. Over high speed (over $1000 \mathrm{r} / \mathrm{min}$ ) makes $R$ decrease because some long-chain polymers are cut off.

4) The drag reduction rate measured in agitator tank device closely fits with drag reduction rate measured in Dongying-Linyi pipeline and Linyi-Puyang pipeline respectively. Using agitator tank device the effect of drag reduction of DRA can be studied in advance. It is very helpful to operate pipeline with DRA.

\section{References}

[1] LI Qun-hai, CAO Dan-fu, CHENG Xu-xia. The application of HG DRA on the Lin-Pu pipeline [J]. Oil \& Gas Storage and Transportation, 2005, 24(7): 56-60. (in Chinese)

[2] DU Xiu-xia, WANG Zhi-liang, ZHANG Zu-hua. The application of DRA on the Dong-Xin pipeline [J]. Oil-Gas Field Surface Engineering, 2006, 25(4): 20-21. (in Chinese)

[3] ZHEN Zai-ci, CAO Dan-fu. The experiment of injecting DRA on the Huang-Qi pipeline [J]. Oil \& Gas Storage and Transportation, 2006, 25(2): 33-37. (in Chinese)

[4] LU Hai-ying, LI Hui-ping, GUAN Min. The testing and analysis of circulating pipeline Indoor evaluation [J]. Oil-Gas Field Surface Engineering, 2003, 22(11): 14-15. (in Chinese)

[5] SHAO Yu-min, GUAN-min, LI Hui-ping. The property research of drag reduction in pipeline $[\mathrm{J}]$. Oil \& Gas Storage and Transportation, 2005, 24(5): 27-30. (in Chinese)

[6] KIM C A, JO A D S, CHOI H J, KIM C B, JHON M S. A high-precision rotating disk apparatus for drag reduction characterization [J]. Polymer Testing, 2001, 20(1): 43-48.

[7] HYOUNG J C, CHUL A K, Jeong-In S, MYUNG S J. An exponential decay function for polymer degradation in turbulent drag reduction [J]. Polymer Degradation and Stability, 2000, 69(3): 341-346.

[8] SOHNA J I, KIM C A, CHOI H J, JHON M S. Drag-reduction effectiveness of xanthan gum in a rotating disk apparatus [J]. Carbohydrate Polymers, 2001, 45(1): 61-68.

[9] KIM C A, KIM J T, LEE K, CHOI H J, JHON M S. Mechanical degradation of dilute polymer solutions under turbulent flow [J]. Polymer, 2000, 41(21): 7611-7615.

[10] LIM S T, PARK S J, CHAN C K, CHOI H J. Turbulent drag reduction characteristics induced by calf-thymus DNA [J]. Physica A 2005, 350(1): 84-88.

[11] CHOI H J, KIM C A, JHON M S. Universal drag reduction characteristics of polyisobutylene in a rotating disk apparatus [J]. Polymer, 1999, 40(16): 4527-4530.

[12] XU Shan-jin. The characteristic testing of drag reduction composite materials PE/PEO/PVC [D]. Faculty of Chemical Engineering, Nanjing University of Technology and Engineering, 2006: 21-23. (in Chinese)

[13] WEI Jin-jia, KAWAGUCHI Y. The characteristic research of Surfactant drag reduction solution in the free rotating flow [J]. Xi'an Jiaotong University Journal, 2006, 40(3): 315-318.

[14] DICKERSON J P, FLESHER L M, HESTER R D. A high Reynolds number rotating disk rheometer [J]. J Appl Rolym Sci, 1994, 53(2): $151-159$.

(Edited by ZHAO Jun) 